\title{
Post-caesarean section surgical site infections: A retrospective audit and case note review at an Ethiopian referral hospital
}

\author{
Rose $\mathrm{AF}^{1 *}$, Fekad B ${ }^{2}$, Moore JN ${ }^{3}$ and Graham WJ ${ }^{4}$ \\ ${ }^{1}$ Academic Foundation Doctor, NHS Greater Glasgow and Clyde, UK \\ ${ }^{2}$ Consultant Obstetrician and Gynaecologist, Felege Hiwot Referral Hospital, Ethiopia \\ ${ }^{3}$ Consultant Anaesthetist, Aberdeen Royal Infirmary, UK \\ ${ }^{4}$ Obstetric Epidemiology, London School of Hygiene and Tropical Medicine, UK
}

\begin{abstract}
In low-income settings, infections acquired during childbirth contribute to maternal mortality and delivery by caesarean section is a leading risk factor, largely due to complications from surgical site infections. The risk of surgical site infection depends on intrinsic (patient) and extrinsic factors.

Objective: To explore the incidence, risk factors and management of post-caesarean surgical site infections at Felege Hiwot Referral Hospital, Bahir Dar, Ethiopia.

Methods: A retrospective audit and case note review of all caesarean deliveries at Felege Hiwot Referral Hospital from $1^{\text {st }}$ October 2016 to 31 st November 2016 . For women who developed a surgical site infection, details of pre- and post-operative management were recorded. Potential associations between surgical site infection and risk factors (including maternal, delivery and operative characteristics) were explored using binary logistic regression to generate odds ratios and $95 \%$ confidence intervals.

Results: Of 1,043 deliveries, 325 were by caesarean (31.2\%) with data available for 247 (76\%). Among nulliparous women ( $\mathrm{n}=117$ ) the leading indication for caesarean was failure to progress in labour $(34 / 117,29.1 \%)$ followed by cephalo-pelvic disproportion $(27 / 117,23.1 \%)$; for parous women, it was previous CS. The overall incidence of surgical site infection was 8.6\% (21 cases), including 14 incisional (14/21, 66.6\%) and 7 organ/space (7/21, 33.3\%). Factors associated with a significantly reduced risk of surgical site infection included attending antenatal care, normal pre-operative haemoglobin, the absence of pregnancy complications and intact membranes before caesarean. A large number of women did not receive pre-operative antibiotic prophylaxis, mostly due to poor prescribing practices.
\end{abstract}

Conclusion: This study highlights the need to improve the use of strategies such as pre-operative prophylactic antibiotic usage in low-income settings, where there may be a higher risk of SSI.

\section{Introduction}

Improving obstetric care in low-income settings is a global priority. Complications arising from infections before, during and after delivery are among the leading causes of death in women of reproductive-age in low-income settings [1-5]. An important risk factor is delivery by Caesarean Section (CS). Following CS, women are up to 20-times more likely to develop an infection compared to those who deliver vaginally $[5,6]$. One of the most important morbidities is post-operative wound infection, or surgical site infection (SSI). As per the Centers for Disease Control and Prevention (CDC) definition [7], a SSI is an infection occurring at the location of a surgical procedure within 30 days of the operation. SSIs can be classified as incisional (superficial) or deep (organ/space). In low-income settings, SSIs are the most prevalent healthcare-associated infection, affecting between $2.5 \%$ and $30.9 \%$ of all operations [8]. The risk of post-CS wound infection depends on both intrinsic (patient-related) and extrinsic factors (management and care) [9]. With CS rates predicted to rise, the incidence of post-CS SSIs will inevitably increase $[8,10]$. Although many patient-related factors are not modifiable, early identification of local risk factors can help to mitigate this risk and prevent the development of a wound infection $[11,12]$. Evaluating the management of SSI post-CS can highlight areas for improved peri-operative management, particularly regarding the use of Antimicrobial Prophylaxis (AMP). Improved outcome is possible through continuous review and quality improvement of service provision. This study aimed to explore the incidence, risk factors and management of post-caesarean surgical site infections at Felege Hiwot Referral Hospital, Bahir Dar, Ethiopia.

\section{Methods}

This was a retrospective audit and case note review of all CS deliveries occurring at Felege Hiwot Referral Hospital (FHRH), Bahir Dar, Ethiopia, from the $1^{\text {st }}$ October 2016 to the $31^{\text {st }}$ November 2016.

Patients eligible for inclusion were all women delivering by CS at FHRH during the specified time period. Following initial screening, records were excluded if they did not include caesarean delivery or did not contain sufficient delivery details. Regarding assessment of preoperative Antimicrobial Prophylaxis (AMP), women who received antibiotics for an indication other than prophylaxis were excluded from this subgroup analysis.

${ }^{*}$ Correspondence to: Anna Rose, Queen Elizabeth University Hospital, NHS Greater Glasgow and Clyde, UK, E-mail: anna.rose@nhs.net

Key words: antibiotics, caesarean, prophylaxis, surgical site infection

Received: August 10, 2018; Accepted: August 24, 2018; Published: August 29 2018 
Data extraction was performed by AR, supervised by BF, using a modified validated data extraction tool [13] from Oasis Global, an international network of infection control professionals. During an initial period of observation, this was adapted to the local population to ensure relevant variables were included. Details included maternal characteristics (age at delivery, parity, pre-operative haemoglobin, HIV and diabetes status, blood pressure at booking), pregnancy characteristics (presence of pre-eclampsia, attendance at antenatal care), delivery characteristics \{type of CS (elective, emergency), whether CS occurred before or after labour onset, membrane status at $\mathrm{CS}$, colour of amniotic fluid, duration of membrane rupture prior to CS, stage of labour (latent first, active first, second stage), duration of labour before CS, duration of time between decision to perform CS and start of operation $\}$ and outcome (alive or stillborn)\}. Finally, operative details (pre-operative antimicrobial prophylaxis, indication for CS, anaesthetic (spinal, general), estimated blood loss, level of operating surgeon, surgical incision, duration of CS) and post-operative details (post-operative antimicrobial prophylaxis, duration of inpatient stay, post-operative complications). Variables were classified according to recognised and reported standards. Surgical wounds were classified according to the time of ROM, as in a recent SSI study in England [14]. If membranes were intact the wound was recorded as 'clean', if the duration between ROM and CS was less than 12 hours 'clean contaminated' and more than 12 hours as 'contaminated'.

Indication for CS was copied from the operation note as decided by the lead surgeon. For cases with more than one indication, a primary indication was selected using the 'Causal Model for Indications of CS' or 'Ontario Classification' as used by Lomas et al. [15]. SSIs were classified according to the CDC definition [7]. Based on written documentation, an incisional SSI was identified by the presence of erythema, local heat and tenderness or discharge from the wound. These were then subdivided into either 'superficial' or 'deep' SSIs according to the depth of tissue involvement. For women who developed a SSI, details on pre- and post-operative management were recorded. Local protocol recommends administering $2 \mathrm{~g}$ IV Ampicillin within a 30-minute window prior to skin incision; post-operatively, three doses of IV Ampicillin (2g) should be given at six-hour intervals unless there are possible signs of sepsis which may warrant a longer course.

Descriptive statistics were used to characterise the study population using either mean (standard deviation) or median (interquartile range) for continuous variables. Rates of CS, both elective and emergency, were calculated as a percentage of all deliveries during the study period. Potential associations between SSI and risk factors (including maternal, delivery and operative characteristics) were explored using binary logistic regression to generate odds ratios and $95 \%$ confidence intervals.

As this study was conducted as a clinical audit, approval to conduct was provided by the usual processes of the Felege Hiwot Quality Assurance department and through the clinical permission of a lead obstetrician for the Maternity Department.

\section{Results}

Of 1043 deliveries at FHRH during the two-month period, a total of 332 CS (31.8\%) were identified and 247 (76\%) cases were analysed (Figure 1). Records were excluded if they did not provide sufficient detail of the delivery $(n=19)$, if the case notes were incorrectly identified from the patient register due to the wrong patient identification number and, as a result, were not applicable $(n=49)$ or if the notes were not available $(n=17)$. Almost half of all mothers were primiparous $(117,47.4 \%)$. Of those, 'failure to progress in labour' was the most frequent indication for CS (34/117, 29.1\%) followed by cephalo-pelvic disproportion (27/117, 23.1\%). For parous women, the leading indication was previous CS $(\mathrm{n}=48 ; 19.6 \%)$.

The overall incidence of SSI at FHRH was $8.6 \%$ of all CS (21/247) (Table 1). Only three cases occurred prior to discharge from hospital, with the remainder presenting on re-admission to FHRH. No data was available for outpatient clinic assessment or if women presented to another healthcare facility. The median time to onset of SSI was postoperative day (POD) 6 (IQR 7), with a range between day 1 and 30 .

Information on the investigations and management was available for 15 cases $(15 / 21,71.4 \%)$, data was incomplete for the remaining six cases. Of the 15 SSIs, all received a full blood count yet only one had blood cultures (6.7\%) and no wound swabs were taken.

Regarding management, two-thirds of SSIs were managed with antibiotics. Of those, 11 (78.6\%) women received intravenous (IV) antibiotics and the remaining three $(21.4 \%)$ were managed with an oral preparation. Most women received a combination of two or more antibiotics $(11,52.4 \%)$. Four women received IV Ceftriaxone and Metronidazole, three women were managed with triple therapy (IV Metronidazole, Ampicillin and Gentamicin) and the remaining

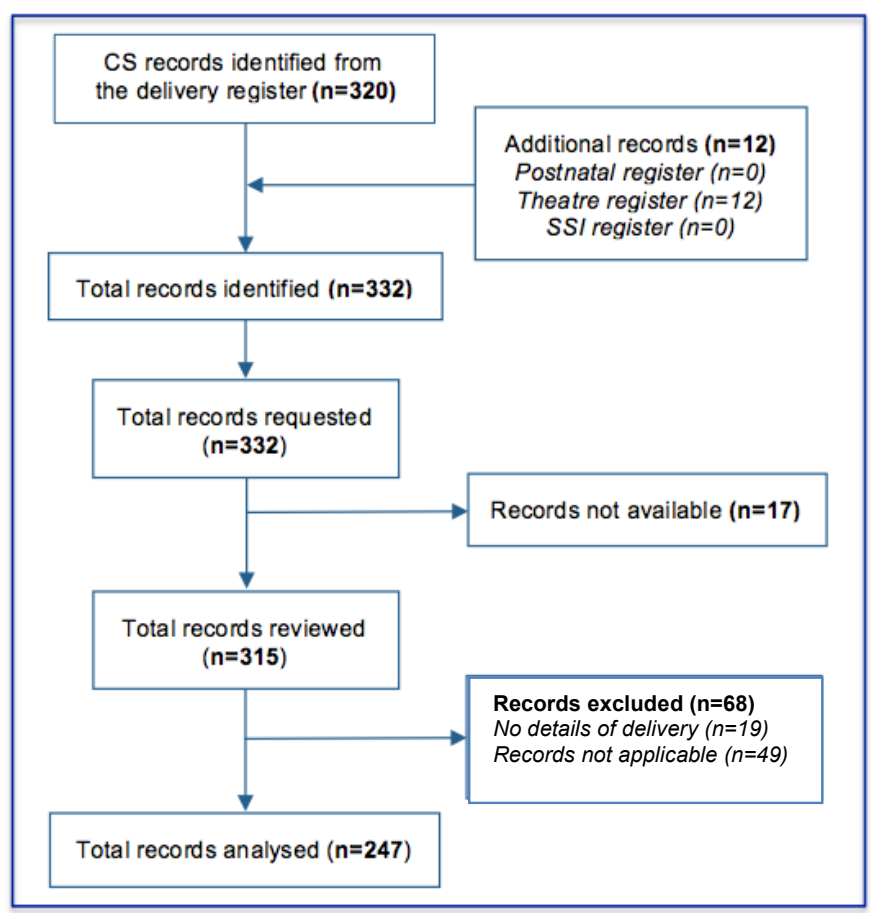

Figure 1. Process to identify cases of Caesarean Section (CS)

Table 1. Type and management of surgical site infections

\begin{tabular}{|l|l|}
\hline Type of SSI (n:21) & Number of cases (\%) \\
\hline Incisional & \\
\hline Organ/space & $14(66.7 \%)$ \\
\hline Treatment for SSI & $7(33.3 \%)$ \\
\hline Observation only & \\
\hline Antibiotics only & $2(9.5 \%)$ \\
\hline Wound exploration & $10(47.6 \%)$ \\
\hline Missing & $3(14.3 \%)$ \\
\hline
\end{tabular}

SSI: Surgical Site Infection 
seven cases were managed with different combinations of the same antibiotics.

An unplanned CS procedure, especially if it occurred after the onset of labour, was associated with an increased risk of SSI (Table 2). Once rupture of membranes (ROM) had occurred, including artificial ROM, the risk of post-CS SSI was greatly increased, and this risk appeared to be proportionate to the time between ROM and CS for both primiparous and parous deliveries. Among primiparous deliveries $(\mathrm{n}=107)$ details on membrane status were available for 89 cases (18 missing). When ROM occurred greater than or equal to 12 hours before CS, the risk of SSI was greater compared to CS less than twelve hours for all deliveries.

Other delivery characteristics associated with an increased risk of SSI include assessment by vaginal examination during labour, a longer labour and an increased 'decision to CS' interval. The greatest increase in SSI risk appeared to be associated with outcome of delivery: two women delivered a stillbirth and were more than 10 times as likely to develop a SSI, but this was not statistically significant.
Non-significant associations with an increased infective risk included younger maternal age (less than 30 years), nulliparity and positive maternal HIV status.

Factors associated with a significantly reduced risk of SSI included attending at least one antenatal care visit, having a normal pre-operative haemoglobin (at least $10 \mathrm{~g} / \mathrm{dl}$ ), a normal blood pressure at booking and not having pre-eclampsia (Table 3 ).

A large number of women did not receive appropriate AMP either before or after surgery, mostly due to poor prescribing practices that meant doses were omitted. Details of pre-operative prophylaxis were available for all CS. Prior to delivery, 17 women $(17 / 247,6.9 \%)$ received antibiotics for an indication other than CS, such as premature ROM or suspected chorioamnionitis and these cases were excluded from further analyses regarding AMP. Of the remaining 230 cases, 63 women $(63 / 230,27.4 \%)$ received appropriate pre-operative AMP in the form of one dose of $2 \mathrm{~g}$ IV Ampicillin while 167 women (167/230, 72.6\%) received no pre-operative antibiotics. Women who received standard

Table 2. Delivery characteristics according to surgical site infection status, with corresponding OR

\begin{tabular}{|c|c|c|c|c|c|c|}
\hline & \multirow{2}{*}{ All CS } & \multirow{2}{*}{ No SSI } & \multirow{2}{*}{ SSI } & \multirow{2}{*}{ OR Unadj. } & \multicolumn{2}{|c|}{ 95\% CI } \\
\hline & & & & & Lower & Upper \\
\hline & $\mathrm{N}: 247$ & n:226 & n:21 & & & \\
\hline \multicolumn{7}{|l|}{ Type of CS } \\
\hline Elective & $37(15 \%)$ & $35(15.5 \%)$ & $2(9.5 \%)$ & 0.57 & 0.13 & 2.58 \\
\hline Emergency & $210(85 \%)$ & $191(84.5 \%)$ & $19(90.5 \%)$ & 1.74 & 0.39 & 7.81 \\
\hline Missing & $0(0 \%)$ & $0(0 \%)$ & $0(0 \%)$ & - & - & - \\
\hline \multicolumn{7}{|l|}{ Outcome } \\
\hline Alive & $244(98.8 \%)$ & $224(99.1 \%)$ & $20(95.2 \%)$ & 0.09 & 0.01 & 1.48 \\
\hline Stillborn & $2(0.8 \%)$ & $1(0.4 \%)$ & $1(4.8 \%)$ & 11.25 & 0.68 & 186.73 \\
\hline \multirow[t]{2}{*}{ Missing } & $1(0.4 \%)$ & $1(0.4 \%)$ & $0(0 \%)$ & - & - & - \\
\hline & $\mathrm{N}: 210$ & $\mathrm{~N}: 191$ & $\mathrm{~N}: 19$ & & & \\
\hline \multicolumn{7}{|l|}{ Emergency CS } \\
\hline Before labour & $26(12.4 \%)$ & $24(12.6 \%)$ & $2(10.5 \%)$ & 0.82 & 0.18 & 3.77 \\
\hline Intrapartum & $184(87.6 \%)$ & $167(87.4 \%)$ & $17(89.5 \%)$ & 1.2 & 0.27 & 5.62 \\
\hline Missing & $0(0 \%)$ & $0(0 \%)$ & $0(0 \%)$ & - & - & - \\
\hline \multicolumn{7}{|l|}{ ROM } \\
\hline Yes & $146(69.5 \%)$ & $132(69.1 \%)$ & $14(73.7 \%)$ & 1.48 & 0.51 & 4.28 \\
\hline No (clean) & $19(9.04 \%)$ & $19(9.9 \%)$ & $0(0 \%)$ & 0.90 & 0.86 & 0.94 \\
\hline Missing & $45(21.4 \%)$ & $40(20.9 \%)$ & $5(26.3 \%)$ & - & - & - \\
\hline \multicolumn{7}{|l|}{ Duration ROM } \\
\hline$<12$ hours $^{\dagger}$ & $63(43.2 \%)$ & $58(43.9 \%)$ & $5(35.7 \%)$ & 0.82 & 0.28 & 2.38 \\
\hline$\geq 12$ hours & $54(37.0 \%)$ & $48(36.4 \%)$ & $6(42.9 \%)$ & 1.38 & 0.50 & 3.82 \\
\hline Missing & $29(19.9 \%)$ & $26(19.7 \%)$ & $3(21.4 \%)$ & - & - & - \\
\hline \multicolumn{7}{|l|}{ VE performed } \\
\hline Yes & $178(84.8 \%)$ & $161(84.3 \%)$ & $17(89.5 \%)$ & 1.58 & 0.35 & 7.21 \\
\hline No & $32(15.2 \%)$ & $30(15.7 \%)$ & $2(10.5 \%)$ & 0.63 & 0.14 & 2.88 \\
\hline Missing & $0(0 \%)$ & $0(0 \%)$ & $0(0 \%)$ & - & - & - \\
\hline \multicolumn{7}{|l|}{ Stage of Labour } \\
\hline Latent first stage & $112(53.3 \%)$ & $102(53.4 \%)$ & $10(52.6 \%)$ & 0.97 & 0.38 & 2.49 \\
\hline Active first stage & $32(15.2 \%)$ & $29(15.2 \%)$ & $3(15.8 \%)$ & 1.05 & 0.29 & 3.82 \\
\hline Second stage & $34(16.2 \%)$ & $30(15.7 \%)$ & $4(21.1 \%)$ & 1.43 & 0.44 & 4.61 \\
\hline Missing & $32(15.2 \%)$ & $30(15.7 \%)$ & $2(10.5 \%)$ & - & - & - \\
\hline \multicolumn{7}{|l|}{ Length of labour } \\
\hline$<8$ hours & $13(6.2 \%)$ & $12(6.3 \%)$ & $1(5.3 \%)$ & 0.83 & 0.10 & 6.75 \\
\hline$\geq 8$ hours & $132(62.9 \%)$ & $119(62.3 \%)$ & $13(68.4 \%)$ & 1.31 & 0.16 & 10.91 \\
\hline Missing & $65(31.0 \%)$ & $60(31.4 \%)$ & $5(26.3 \%)$ & - & - & - \\
\hline \multicolumn{7}{|l|}{ Decision to CS } \\
\hline$<75$ mins & $61(29.0 \%)$ & $58(30.4 \%)$ & $3(15.8 \%)$ & 0.43 & 0.12 & 1.53 \\
\hline$\geq 75$ mins & $61(29.0 \%)$ & $56(29.3 \%)$ & $5(26.3 \%)$ & 1.73 & 0.40 & 7.60 \\
\hline Missing & $88(41.9 \%)$ & $77(40.3 \%)$ & $11(57.9 \%)$ & - & - & - \\
\hline
\end{tabular}

CS: Caesarean section; ROM: Rupture of membranes; ${ }^{\dagger}$ ROM $<12$ hours: clean contaminated; ${ }^{\star}$ ROM $>12$ hours: contaminated; VE: Vaginal examination, OR: Odds ratio, unadjusted for other variables; $95 \%$ CI: $95 \%$ confidence interval; Bold denotes statistically significant results 
Table 3. Maternal and pregnancy characteristics according to surgical site infection status, with corresponding OR

\begin{tabular}{|c|c|c|c|c|c|c|}
\hline & \multirow{2}{*}{ All CS } & \multirow{2}{*}{ No SSI } & \multirow{2}{*}{ SSI } & \multirow{2}{*}{$\begin{array}{l}\text { OR } \\
\text { Unadj. }\end{array}$} & \multicolumn{2}{|c|}{$95 \%$ CI } \\
\hline & & & & & Lower & Upper \\
\hline & $\mathrm{N}: 247$ & n:226 & n:21 & & & \\
\hline \multicolumn{7}{|l|}{ Age } \\
\hline$<30$ years & $175(70.9 \%)$ & $157(6.9 \%)$ & $18(85.7 \%)$ & 2.48 & 0.71 & 8.72 \\
\hline$\geq 30$ years & $72(29.1 \%)$ & $69(30.5 \%)$ & $3(14.3 \%)$ & 0.40 & 0.12 & 1.41 \\
\hline Missing & $0(0 \%)$ & $0(0 \%)$ & $0(0 \%)$ & - & - & - \\
\hline \multicolumn{7}{|l|}{ Parity } \\
\hline Nulliparous & $117(47.4 \%)$ & $103(45.6 \%)$ & $14(66.7 \%)$ & 2.35 & 0.91 & 6.04 \\
\hline Multiparous & $128(51.8 \%)$ & $121(53.5 \%)$ & $7(33.3 \%)$ & 0.43 & 0.17 & 1.1 \\
\hline Missing & $2(0.8 \%)$ & $2(0.8 \%)$ & $0(0 \%)$ & - & - & - \\
\hline \multicolumn{7}{|l|}{ ANC } \\
\hline No ANC & $6(2.4 \%)$ & $6(2.7 \%)$ & $0(0 \%)$ & - & - & - \\
\hline ANC & $230(93.1 \%)$ & $211(93.4 \%)$ & $19(90.5 \%)$ & 0.97 & 0.95 & 0.99 \\
\hline Missing & $11(4.5 \%)$ & $9(4.0 \%)$ & $2(9.5 \%)$ & - & - & - \\
\hline \multicolumn{7}{|l|}{ EGA } \\
\hline$<37$ weeks & $26(10.5 \%)$ & $24(10.6 \%)$ & $2(1.0 \%)$ & 1.10 & 0.29 & 4.27 \\
\hline$\geq 37$ weeks & $176(71.3 \%)$ & $161(71.2 \%)$ & $15(71.4 \%)$ & 0.89 & 0.82 & 1.18 \\
\hline Missing & $45(18.2 \%)$ & $41(18.1 \%)$ & $4(19.0 \%)$ & - & - & - \\
\hline \multicolumn{7}{|l|}{ Pre-op Hb } \\
\hline$<10 \mathrm{~g} / \mathrm{dl}$ & $6(2.4 \%)$ & $6(2.7 \%)$ & $0(0 \%)$ & - & - & - \\
\hline$\geq 10 \mathrm{~g} / \mathrm{dl}$ & $124(50.2 \%)$ & $113(50 \%)$ & $11(52.4 \%)$ & 0.95 & 0.91 & 0.99 \\
\hline Missing & $117(47.4 \%)$ & $107(47.3 \%)$ & $10(47.6 \%)$ & - & - & - \\
\hline \multicolumn{7}{|l|}{ HIV status } \\
\hline HIV negative & $99(40.1 \%)$ & $92(40.7 \%)$ & $7(33.3 \%)$ & 0.38 & 0.04 & 3.72 \\
\hline HIV positive & $6(5.7 \%)$ & $5(2.2 \%)$ & $1(4.8 \%)$ & 2.64 & 0.27 & 25.71 \\
\hline Missing & $142(57.5 \%)$ & $129(57.1 \%)$ & $13(62.0 \%)$ & - & - & - \\
\hline \multicolumn{7}{|l|}{ Diabetes } \\
\hline Yes & $1(0.4 \%)$ & $1(0.4 \%)$ & $0(0 \%)$ & - & - & - \\
\hline No & $246(99.6 \%)$ & $225(99.6 \%)$ & $21(100 \%)$ & 0.99 & 0.99 & 1.00 \\
\hline Missing & $0(0 \%)$ & $0(0 \%)$ & $0(0 \%)$ & - & - & - \\
\hline \multicolumn{7}{|l|}{ Hypertension } \\
\hline Yes & $6(2.4 \%)$ & $6(2.7 \%)$ & $0(0 \%)$ & - & - & - \\
\hline No & $241(97.6 \%)$ & $220(97.3 \%)$ & $21(100 \%)$ & 0.97 & 0.95 & 0.99 \\
\hline Missing & $0(0 \%)$ & $0(0 \%)$ & $0(0 \%)$ & - & - & - \\
\hline \multicolumn{7}{|l|}{ PET } \\
\hline Yes & $22(89.1 \%)$ & $22(9.7 \%)$ & $0(0 \%)$ & - & - & - \\
\hline No & $225(91.1 \%)$ & $204(90.3 \%)$ & $21(100 \%)$ & 0.90 & 0.87 & 0.94 \\
\hline Missing & $0(0 \%)$ & $0(0 \%)$ & $0(0 \%)$ & - & - & - \\
\hline
\end{tabular}

ANC: Antenatal Care (did the woman attend at least one visit), EGA: Estimated Gestational Age (in completed weeks), Pre-op Hb: Pre-operative haemoglobin level, HIV: Human Immunodeficiency Virus status, PET: Pre-eclampsia status, OR: Odds ratio, unadjusted for other variables, $95 \%$ CI: $95 \%$ confidence interval, Bold denotes statistically significant results.

pre-operative AMP $(n=63)$ were then compared to those who received no antibiotics $(n=167)$. Receiving pre-operative AMP was associated with a reduced risk of developing SSI but the result was not statistically significant (Table 4).

For post-operative antibiotics, 219 of 247 women (88.7\%) received the standard post-operative antibiotic regimen (three doses of IV Ampicillin, 2g). The remaining 28 women (11.3\%) did not received post-operative AMP.

Overall, there were few statistically significant findings so multivariate analysis was unwarranted [16].

\section{Discussion}

An institutional CS rate of $31.8 \%$ reflects the case-mix at this hospital: the greater the number of referrals, the more complex the services offered, and the greater the number of CS. Furthermore, as the only tertiary referral hospital in Bahir Dar, it is anticipated that the CS rate at FHRH will be high [17]. When analysing type of CS, an unplanned procedure, especially if it occurred after the onset of labour, was associated with an increased risk of SSI. A high CS rate among primiparous women is extremely important because of the subsequent increased risk of CS, compared to VD, in future pregnancies [18]. This further contributes to rising CS rates.

The finding of a SSI rate of $8.6 \%$ is consistent with other studies: a recent report of four hospitals in sub-Saharan Africa by Chu et al. [19] identified a SSI rate of 7.3\% and a national review of CS delivery across different hospitals in Ethiopia calculated an incidence of postCS SSI as $12 \%$ [17]. In comparison, a prospective study of CS at a tertiary referral hospital in Tanzania found almost half of all CS were complicated by SSI (48\%, 224 cases) [16]. Regarding other countries, a Jordanian hospital [17] identified an SSI rate of $14.4 \%$ and Wloch et al. [14], in their study of 14 English maternity hospitals, calculated a post-CS rate of $9.6 \%$. Of interest, the methodology used by Wloch et al. [14] differed since patients were actively followed up. In our study, SSIs were only identified if women were re-admitted to FHRH. This suggests our result is likely an underestimate as many patients will not 
Table 4. Operative characteristics according to surgical site infection status, with corresponding OR

\begin{tabular}{|c|c|c|c|c|c|c|}
\hline & \multirow{2}{*}{ All CS } & \multirow{2}{*}{ No SSI } & \multirow{2}{*}{ SSI } & \multirow{2}{*}{$\begin{array}{l}\text { OR } \\
\text { Unadj. }\end{array}$} & \multicolumn{2}{|c|}{$95 \%$ CI } \\
\hline & & & & & Lower & Upper \\
\hline & n:230 & n:212 & n:18 & & & \\
\hline \multicolumn{7}{|l|}{ Received AMP ${ }^{\dagger}$} \\
\hline Yes & $63(27.4 \%)$ & $59(13.7 \%)$ & $4(22.2 \%)$ & 0.74 & 0.23 & 2.34 \\
\hline No & $167(72.6 \%)$ & $153(72.2 \%)$ & $14(77.8 \%)$ & 1.35 & 0.43 & 4.27 \\
\hline \multirow[t]{2}{*}{ Missing } & $0(0 \%)$ & $0(0 \%)$ & $0(0 \%)$ & - & - & - \\
\hline & $\mathrm{N}: 247$ & $\mathrm{n}: 226$ & $\mathrm{n}: 21$ & & & \\
\hline \multicolumn{7}{|l|}{ Anaesthetic } \\
\hline Spinal & $229(92.7 \%)$ & $209(92.5 \%)$ & $20(95.2 \%)$ & 1.63 & 0.21 & 12.87 \\
\hline General & $18(7.3 \%)$ & $17(7.5 \%)$ & $1(4.8 \%)$ & 0.62 & 0.08 & 4.86 \\
\hline Missing & $0(0 \%)$ & $0(0 \%)$ & $0(0 \%)$ & - & - & - \\
\hline \multicolumn{7}{|l|}{ Blood loss } \\
\hline$<500 \mathrm{ml}$ & $177(71.7 \%)$ & $164(72.6 \%)$ & $13(61.9 \%)$ & 0.61 & 0.24 & 1.55 \\
\hline$\geq 500 \mathrm{ml}$ & $62(25.1 \%)$ & $55(24.3 \%)$ & $7(33.3 \%)$ & 1.56 & 0.60 & 4.05 \\
\hline Missing & $8(3.2 \%)$ & $7(3.1 \%)$ & $1(4.8 \%)$ & - & - & - \\
\hline \multicolumn{7}{|l|}{ Level of surgeon } \\
\hline Junior (R1, R2, R3) & $223(90.3 \%)$ & $204(90.3 \%)$ & $19(90.5 \%)$ & 1.03 & 0.22 & 4.70 \\
\hline Senior (R4, cons) & $20(8.1 \%)$ & $20(8.8 \%)$ & $0(0 \%)$ & - & - & - \\
\hline Missing & $4(1.6 \%)$ & $2(0.9 \%)$ & $2(9.5 \%)$ & - & - & - \\
\hline \multicolumn{7}{|l|}{ Skin incision } \\
\hline Pfannenstiel & $233(94.3 \%)$ & $214(94.7 \%)$ & $19(90.5 \%)$ & 0.53 & 0.11 & 2.56 \\
\hline Midline & $14(5.7 \%)$ & $12(5.3 \%)$ & $2(9.5 \%)$ & 1.88 & 0.39 & 9.01 \\
\hline Missing & $0(0 \%)$ & $0(0 \%)$ & $0(0 \%)$ & - & - & - \\
\hline \multicolumn{7}{|l|}{ Duration of CS } \\
\hline$<1$ hour & $124(50.2 \%)$ & $112(49.6 \%)$ & $12(57.1 \%)$ & 1.50 & 0.54 & 4.16 \\
\hline$\geq 1$ hour & $90(36.4 \%)$ & $84(37.2 \%)$ & $6(28.6 \%)$ & 0.67 & 0.24 & 1.85 \\
\hline Missing & $33(13.4 \%)$ & $30(13.3 \%)$ & $3(14.3 \%)$ & - & - & - \\
\hline \multicolumn{7}{|l|}{ Post-op stay } \\
\hline$\leq 3$ days & $152(61.5 \%)$ & $143(63.3 \%)$ & $9(42.9 \%)$ & 1.11 & 0.29 & 4.26 \\
\hline$>3$ days & $56(22.7 \%)$ & $53(23.5 \%)$ & $3(14.3 \%)$ & 0.90 & 0.24 & 3.45 \\
\hline Missing & $39(15.8 \%)$ & $30(13.3 \%)$ & $9(42.9 \%)$ & - & - & - \\
\hline
\end{tabular}

†AMP: Antimicrobial Prophylaxis, one dose of $2 \mathrm{~g}$ intravenous Ampicillin, Pre-op: pre-operative, CS Caesarean Section, Level of surgeon (R indicates resident; cons: consultant)

return to FHRH for follow-up. In addition, these figures are lower than those reported in some high-income countries which would suggest under-ascertainment in low and middle-income countries [17].

The time between CS and SSI detection is similar to results from both Chu et al. [19] and Mpogoro et al. [22] who identified a median date of detection of the 6th and 7th post-operative day, respectively.

Our finding of a greater incidence of superficial SSIs, compared to deep infections, is also in agreement with Chu et al. [19] who calculated that $93 \%$ of SSIs within their population were superficial. Finally, Chu et al. also identified younger maternal age (less than or equal to 30 years), premature ROM and neonatal death as leading risk factors for post-CS wound infection and these remained statistically significant after adjustment for relevant patient and operative factors, whereas in our Ethiopian study they were not.

Identifying an increased incidence of SSIs among emergency CS is consistent with results from Mpogoro et al. [20] who found that, of 345 CS, SSIs only affected emergency procedures. Results from Hadar et al. [21] concur that intrapartum CS appears to be associated with an increased SSI risk.

In our results, the risk of post-CS SSI was greatly increased following labour onset and ROM, and this risk appeared to be proportionate to the time between ROM and CS. Krieger et al. [22] analysed more than 40,000 CS deliveries in Israel and identified a significant association between premature ROM and risk of subsequent SSI. This has clinical implications as, where possible, the delay between ROM and CS delivery should be minimised or appropriate antibiotic prophylaxis given.

Strengths of this study include data collection: data were collated from four sources to maximise the chance of including all relevant cases. Variables were classified according to recognised reports, removing the effect of misclassification bias. Due to the retrospective nature of this study, there are several limitations. Patients were not actively followed up after discharge and were only recorded if they re-presented with a complication which is important since many post-operative infections occur following hospital discharge [14]. This single-centre audit also did not account for patients returning to smaller healthcare centres. One key study limitation is the proportion of missing data, both individual cases and specific variables. For missing case notes, this further raises the possibility of under-ascertainment of post-operative infection. Regarding missing variables, one example is maternal body mass index that is not routinely collected yet is a strong predictor of post-CS complications [13]. Finally, environmental risk factors were not specifically addressed, particularly cleaning of the operating theatre and sterility of the surgical field.

There are two main concerns in the prevention and management of SSIs: poor use of pre-operative antibiotic prophylaxis and poor documentation, leading to omission of doses post-operatively and when treating recognised SSIs. This has significant implications for the outcomes of women undergoing CS and also contributes to rising antimicrobial resistance. 
At a time of rising operative delivery rates around the world, this paper is extremely relevant in highlighting the risk of post-operative wound infection following CS delivery $[23,24]$. The results of this study further reinforce the importance of rigorous screening for infection and the role of antibiotics, in both prevention and treatment. Although some patient-related factors are not modifiable, early identification of locally-relevant risk factors may help to mitigate this risk and prevent the development of infections. Efforts should be made to reduce the risk of SSI as well as to reduce routine practice of repeat CS. This may be achieved by identifying women at an increased risk of CS and adopting best practice management. Furthermore, prevention is better than cure: appropriate use of AMP can prevent SSI and practice should be changed to improve antibiotic prescribing and documentation, particularly in the face of emerging resistance.

\section{Ethical statement}

Approval was provided by the usual processes of the Felege Hiwot Quality Assurance department and through the clinical permission of a lead obstetrician for the Maternity Department (BF).

\section{Acknowledgements}

We thank the administrative and clinical staff of the maternity department at FHRH, Ethiopia, for their contributions to data collection and allowing the audit to take place.

\section{Funding sources}

A. Rose received funding from several sources to complete this audit while an undergraduate medical student (The Hospital Saturday Fund, The British Medical and Dental Students' Trust, The European Wound Management Association, The Highland Council Ross \& Cromarty Educational Trust and The Royal College of Physicians and Surgeons of Glasgow).

\section{References}

1. Miller S, Abalos E, Chamillard M, Ciapponi A, Colaci D, et al. (2016) Beyond too little, too late and too much, too soon: a pathway towards evidence-based, respectful maternity care worldwide. Lancet 388: 2176-2192. [Crossref]

2. Perencevich EN, Sands KE, Cosgrove SE, Guadagnoli E, Meara E, et al. (2003) Health and economic impact of surgical site infections diagnosed after hospital discharge. Emerg Infect Dis 9: 196-203. [Crossref]

3. Berg CJ, Chang J, Callaghan WM, Whitehead SJ (2003) Pregnancy-related mortality in the United States, 1991-1997. Obstet Gynecol 101: 289-296. [Crossref]

4. Graham W, Woodd S, Byass P, Filippi V, Gon G, et al. (2016) Diversity and divergence: the dynamic burden of poor maternal health. Lancet 388: 2164-2175. [Crossref]

5. Leth RA, Moller JK, Thomsen RW, Uldbjerg N, Norgaard M (2009) Risk of selected postpartum infections after cesarean section compared with vaginal birth: a five-year cohort study of 32,468 women. Acta Obstet Gynecol Scand 88: 976-983. [Crossref]
6. van Dillen J, Zwart J, Schutte J, van Roosmalen J (2010) Maternal sepsis: epidemiology, etiology and outcome. Curr Opin Infect Dis 23: 249-254. [Crossref]

7. Horan TC, Andrus M, Dudeck MA (2008) CDC/NHSN surveillance definition of health care-associated infection and criteria for specific types of infections in the acute care setting. Am J Infect Control 36: 309-332. [Crossref]

8. Allegranzi B, Bagheri SN, Combescure C, Graafmans W, Attar H, et al. (2011) Burden of endemic health-care-associated infection in developing countries: systematic review and meta-analysis. Lancet 377: 228-241. [Crossref]

9. Mangram AJ, Horan TC, Pearson ML, Silver LC, Jarvis WR (1999) Guideline for prevention of surgical site infection, 1999. Hospital Infection Control Practices Advisory Committee. Infect Control Hosp Epidemiol 20: 250-278. [Crossref]

10. Gibbons L, Belizan JM, Lauer JA, Betran AP, Merialdi M, et al. (2010) The Globa Numbers and Costs of Additionally Needed and Unnecessary Caesarean Sections Performed per Year: Overuse as a Barrier to Universal Coverage.

11. World Health Organisation. Report on the burden of endemic health care-associated infection worldwide. Geneva: World Health Organisation 2011.

12. Johnson A, Young D, Reilly J (2006) Caesarean section surgical site infection surveillance. J Hosp Infect 64: 30-35. [Crossref]

13. Solomkin JS (2015) Surgical Site Infection Prevention: International Consensus on Process.

14. Wloch C, Wilson J, Lamagni T, Harrington P, Charlett A, et al. (2013) Risk factors for surgical site infection following caesarean section in England. BJOG 120: 509-510. [Crossref]

15. Anderson GM, Lomas J (1989) Recent trends in cesarean section rates in Ontario. CMAJ 141: 1049-1053. [Crossref]

16. Ho R (2006) Handbook of Univariate and Multivariate Data Analysis and Interpretation with SPSS. (1st ed.) New York: Taylor \& Francis Group. [Crossref]

17. Fesseha N, Getachew A, Hiluf M, Gebrehiwot Y, Bailey P (2011) A national review of cesarean delivery in Ethiopia. Int J Gynaecol Obstet 115: 106-111. [Crossref]

18. Haerskjold A, Hegaard HK, Kjaergaard H (2012) Emergency caesarean section in low risk nulliparous women. J Obstet Gynaecol 32: 543-547. [Crossref]

19. Chu K, Maine R, Trelles M (2015) Cesarean section surgical site infections in subSaharan Africa: a multi-coutnry study from Medecins Sans Frontieres. World J Surg 39: 350-355. [Crossref]

20. Mpogoro FJ, Mshana SE, Mirambo MM, Kidenya BR, Gumodoka B, et al. (2014) Incidence and predictors of surgical site infections following caesarean sections at Bugando Medical Centre, Mwanza, Tanzania. Antimicrob Resist Infect Control 3: 25. [Crossref]

21. Hadar E, Melamed N, Tzadikevitch-Geffen K, Yogev Y (2011) Timing and risk factors of maternal complications of cesarean section. Arch Gynecol Obstet 283: 735-741. [Crossref]

22. Krieger Y, Walfisch A, Sheiner E (2016) Surgical site infection following cesarean deliveries: trends and risk factors. J Matern Fetal Neonatal Med 30: 8-12. [Crossref]

23. Appropriate technology for birth. Lancet 2: 436-437. [Crossref]

24. World Health Organisation. WHO Statement on Caesarean Section Rates. 2015:1-8.

Copyright: (C2018 Rose AF. This is an open-access article distributed under the terms of the Creative Commons Attribution License, which permits unrestricted use, distribution, and reproduction in any medium, provided the original author and source are credited. 